\title{
Frontera e integridad en el «contrato social para la ciencia española», 1907-1939
}

\author{
Amparo Gómez (*) \\ $\left({ }^{*}\right)$ Departamento de Historia y Filosofía de la Ciencia, la Educación y el Lenguaje, \\ Universidad de La Laguna. \\ agomez@ull.es
}

Dynamis

[0211-9536] 2014; 34 (2): 465-487

http://dx.doi.org/10.4321/S0211-95362014000200010
Fecha de recepción: 12 de diciembre de 2012

Fecha de aceptación: 18 de noviembre de 2013

SUMARIO: 1.-Introducción. 2.-El contrato social para la ciencia española. 3.-El control político de la JAE: la frontera entre ciencia y política. 4.-Las redes de influencia y el partidismo de la JAE: problemas de integridad. 5.-La gestión de los fondos. 6.-Conclusiones.

RESUMEN: En este artículo se analizan las relaciones entre ciencia y política en el primer tercio del siglo XX español desde la perspectiva del Contrato Social para la Ciencia. En él se muestra que en dicho periodo se instituyó un auténtico contrato social para la ciencia en España, aunque surgieron algunos problemas de frontera e integridad. Dichos problemas son analizados y se defiende que los problemas de frontera fueron resultado de la concepción de las relaciones entre ciencia y política de los gobiernos conservadores, mientras que los problemas de integridad tuvieron que ver con la activación de redes de influencia en la concesión de las becas para la formación en el extranjero. Finalmente, el análisis revela que estos problemas no invalidaron el contrato social para la ciencia en España.

PALABRAS CLAVE: política de la ciencia, contrato social para la ciencia, frontera entre ciencia y política, integridad, productividad, Junta para la Ampliación de Estudios e Investigaciones Científicas.

KEY WORDS: Science policy, social contract for science, boundary between science and politics, integrity, productivity, Board for Advanced Studies and Scientific Research. 


\section{Introducción $(*)$}

El «contrato social para la ciencia» es un modelo teórico de las relaciones entre ciencia y política basado en una analogía con el contrato social de la teoría política ${ }^{1}$. Este modelo aborda la intervención de los Estados modernos en el desarrollo científico de los países como un contrato entre científicos y políticos que especifica derechos y obligaciones. Dicho contrato sería resultado, por un lado, del reconocimiento por los gobiernos de la importancia de la ciencia y la tecnología para el desarrollo de los países; por otro, del reconocimiento por los científicos de la importancia de que los gobiernos proporcionen recursos económicos y pongan en marcha políticas que permitan desarrollar la investigación científica en las mejores condiciones.

El contrato implica dos asunciones fundamentales que son definitorias del modelo: a) la existencia de una frontera entre ciencia y política que garantiza la independencia de la ciencia ${ }^{2}$ y b) la integridad y la productividad de los científicos que garantiza la producción de buena ciencia y tecnología ${ }^{3}$. El fundamento de estas asunciones se encuentra en los propios estándares y valores que constituyen la episteme científica y, también, la «moral de la

(*) Este artículo se ha elaborado gracias al apoyo del Proyecto de Investigación FFI2009-09483 del Ministerio de Ciencia e Innovación y del Proyecto FFI2012-33998 del Ministerio de Economía y Competitividad.

1. Kleinman, Daniel L. Politics on the endless frontier. Postwar research policy in the United States. Durham and London: Duke University Press; 1995. Guston, David H.; Keniston, Kenneth, eds. The fragile contract. University science and Federal Government. Massachussetts: The MIT Press; 1994. Guston, David H. Between politics and science. Assuring the integrity and productivity of research. Cambridge: Cambridge University Press; 2000. Schmaus, Michael. Science and the social contract in renouvier. The Journal of the International Society for the History of Philosophy of Science. 2011; 1: 73-100. Rhoades, Gary; Slaughter, Sheila. From endless frontier to basics Science for use: Social contracts between science and society. Science, Technology, and Human Values. 2005; 30 (4): 536-572. Lubchenco, Jane. Entering the Century of the environment: A new social contract for science. Science. 1998; 279 (5350): 491-497. Gibbons, Michael. Science's new social contract with society. Nature. 1999; 402: 8194. Demeritt, David. The new social contract for science: Accountability, relevance, and value in US and UK science and research policy. Antipode. 2000; 32 (3): 308-329.

2. A partir de los años setenta y dada la complejidad del propio desarrollo científico, el modelo admite un mayor protagonismo político aunque no se cuestiona la necesidad de cuotas de autonomía para la ciencia. Véase la interesante reflexión de Kitcher acerca de una ciencia bien ordenada y sus condiciones de posibilidad en las sociedades democráticas: Kitcher, Phillip. Science, truth, and democracy. Oxford: Oxford University Press; 2001.

3. Como señala Kleinman, n. 1, p. 2, «scientific practice was and should be independent of the rest of society and the scientific community should be responsible only to itself». 
ciencia» ${ }^{4}$. Teóricamente, ambas son asumidas por los científicos y por los políticos como consustanciales a la práctica científica y su desarrollo. Todo lo que se necesita para que la ciencia (y la tecnología) florezca es disponer de libertad y de fondos suficientes. Esto es lo que garantiza el contrato social para la ciencia.

Otras asunciones del modelo tienen que ver con su aplicación al análisis de casos históricos. En este ámbito prevalece la idea de que las relaciones entre ciencia y política características del contrato social para la ciencia se habrían dado en los países occidentales sobre todo después de la Segunda Guerra Mundial, constituyendo una auténtica «edad de oro ${ }^{5}$ en la que científicos responsables investigaban para el Estado que proveía de financiación sin intervenir ni en la ciencia, ni en su gobierno ${ }^{6}$. No obstante, se admite que, en la medida en que la ciencia atrajo el interés de los gobiernos desde mucho antes, es posible encontrar precedentes del contrato, al menos desde finales del XIX (como han señalado, entre otros, Guston, Kleinman, Pielke o Cancelado) e incluso auténticos contratos después de la Primera Guerra

4. La moral de la ciencia supuso oponer en los diferentes ámbitos de la vida pública, como ocurrió en España, la objetividad, la neutralidad, la observación desapasionada, la precisión, la rigurosidad, como nueva moral basada en la ciencia al dominio de la religión, la tradición, las ideologías y la vieja moral. Frente a la red de influencias, el privilegio y la corrupción se defendía la independencia de criterio, la integridad, la discusión pública y abierta, la razón y la responsabilidad. La moral de la ciencia fue defendida por krausistas, regeneracionistas y positivistas. Véase Ureña, Enrique M. El «ideal de la humanidad» de Sanz del Río $(1851,1860)$ y su original alemán. El Basilisco: Revista de filosofía, ciencias humanas, teoría de la ciencia y de la cultura. 1992; 12: 75-97. Lafuente, Antonio. España un objeto experimental. In: Sánchez Ron, José Manuel; Lafuente, Antonio; Romero, Ana; Sánchez de Andrés, Leticia, eds. El Laboratorio de España. La Junta para la Ampliación de Estudios e Investigaciones Científicas 1907-1939. Madrid: Sociedad Estatal de Conmemoraciones Culturales y Residencia de Estudiantes; 2007, p.129-135.

5. La expresión «edad de oro» se usa en el sentido de la mejor o más brillante época de algo, en este caso del contrato social para la ciencia.

6. Estas serían las relaciones entre ciencia y política que se darían desde la Segunda Guerra Mundial a los años setenta. Véase Bush, Vannevar. Science: The endless frontier. Transactions Kansas Academy of Science. 1945; 48 (3): 231-264. Price, Krasher D. Government and science: Their dynamic relation in American democracy. New York: New York University Press; 1954. Steelman, John R. Science and public policy. Washington DC: U.S.G.P.O.; 1947. Hay que resaltar que en este periodo aparece la Guerra Fría con lo que la investigación militar tuvo un importante papel para los gobiernos; véase por ejemplo, Balmer, Brian. Britain and biological warfare expert advice and science policy, 1930-65. Basingstoke: Palgrave; 2001. Balmer, Brian. Secrecy and science: A Historical sociology of biological and chemical warfare. Fanham: Ashgate; 2012. 
Mundial $^{7}$. En segundo lugar, se considera que a partir de los años setenta, dadas las características de la ciencia reciente, las asunciones del contrato social para la ciencia dejaron de ser siempre, y totalmente, satisfechas, al menos en su versión clásica ${ }^{8}$. Esto está dando lugar a una revisión del modelo, que se mantiene en una versión más sofisticada bajo el epígrafe de «nuevo contrato social para la ciencia»?

Por otro lado, el modelo clásico del contrato social sigue siendo un interesante instrumento analítico y está permitiendo examinar desde diferentes ángulos casos históricos conocidos sobre los que arroja nueva luz. Esto es lo que se hace en este artículo con su aplicación al análisis de las relaciones entre ciencia y política que se instituyeron en España entre 1907 y 1939. La hipótesis que guía esta investigación es que dichas relaciones constituyeron un auténtico contrato social para la ciencia, a pesar de que se dieran algunos problemas de frontera entre ciencia y política y de integridad. Con la aplicación del modelo a este caso se pretende mostrar: a) que dicho contrato existió antes de la Segunda Guerra Mundial y que, por tanto, el modelo puede aplicarse al estudio de las relaciones entre ciencia y política desde comienzos del siglo XX, y b) que, incluso en los periodos históricos clásicos, las relaciones entre ciencia y política presentan ciertos aspectos que no encajan completamente en el modelo.

En primer lugar, se caracterizará el contrato social para la ciencia en España y se mostrará que su formulación asumió la autonomía de la ciencia, la integridad y la productividad científicas. En segundo, se abordarán los problemas de frontera que surgieron. En tercer lugar, se analizará el

7. Pielke analiza estas relaciones en EE.UU. entre 1850-1940 y, sobre todo, después de la I Guerra Mundial cuando él cree que se establecieron auténticos contratos sociales para la ciencia; véase Pielke, Roger. The honest broker. Making sense of science in policy and politics. Cambridge: Cambridge University Press; 2007. Guston, n. 1, p. 3, 6, 8, 32-36. Kleinman, n. 1, p. 24-51. Cancelado, Manuel. Contrato social de la ciencia, una necesidad en las sociedades del conocimiento. Revista Universidad de La Salle. 2007; 44: 30-32. Un ejemplo de tal contrato «no escrito» fue el «Principio Haldane» que garantizó en Inglaterra la independencia entre ciencia y política al principio del siglo XX. Este principio lleva el nombre de Richard Burdon Haldane, quien entre 1909 y 1918 recomendó está política de la ciencia.

8. Guston, n. 1, p. 144; Kleinman, n. 1, p. 4.

9. En relación al Nuevo contrato social para la ciencia, véanse Rhoades; Slaughter, n. 1, p. 536-572. Schmaus, n. 1, p. 73-100. Gibbons, n. 1, p. 81-94. Gómez, Amparo; Balmer, Brian. Ciencia y política: una cuestión de frontera. In: Gómez, Amparo; Canales, Antonio Francisco. Estudios Políticos de la ciencia. Política y Desarrollo científico en el siglo XX. Madrid: Plaza y Valdés; 2013, p. 15-34. Lubchenco, n. 1, p. 491-497. Demeritt, n. 1, p. 308-329. 
problema de integridad que se dio en la concesión de becas de estudio en el extranjero. En cuarto lugar, se examinarán las críticas conservadoras a la gestión de los fondos concedidos por el Gobierno. El tratamiento de estos puntos tendrá en cuenta el debate entre conservadores y liberales acerca de la política de la ciencia que debía llevarse a cabo en España y el efecto que sobre el contrato social para la ciencia tuvieron las dos concepciones que se enfrentaron. Finalmente se señalará la alta productividad de este contrato y se concluirá con algunas consideraciones acerca de la relevancia del contrato social para la ciencia española a pesar de los problemas identificados.

\section{El contrato social para la ciencia española}

El periodo comprendido entre 1907 y 1939 fue uno de los más fructíferos de la ciencia en nuestro país, y puede denominarse «edad de plata» de la ciencia española ${ }^{10}$. El desarrollo científico logrado en estos años fue resultado de la implantación de una política de la ciencia que persiguió dos objetivos principales: mejorar la educación científica con becas de estudios en el extranjero (también en España) y promover la investigación científica proporcionando los recursos financieros necesarios para ello. Esta política fue resultado de dos importantes factores que convergieron en el cambio de siglo: a) una clara conciencia de la élite científica e intelectual española acerca de la importancia clave de la ciencia y la tecnología para el progreso del país ${ }^{11}$ y b) el acuerdo entre esta élite y los políticos acerca de la necesidad de desarrollar medidas políticas para mejorar la investigación y la formación científica española.

10. En la literatura acerca de este periodo aparece el término «edad de plata de las letras y ciencias españolas». El término es acuñado por Mainer, José-Carlos. La Edad de Plata (1902-1939). Madrid: Editorial Cátedra; 1981. Véase por ejemplo, Ausejo Martínez, Elena. Sobre la Edad de Plata de la Ciencia española: a vueltas con los metales. Abaco: Revista de cultura y ciencias sociales. 2004; núm. 42: 75-82.

11. Esta conciencia se fue constituyendo desde mediados del siglo XIX dado el retraso científico técnico español y las deficientes condiciones en las que se desarrollaba en España la investigación y la enseñanza científica. Ramón y Cajal señalaba que «la posteridad de las naciones es obra de la ciencia y sus aplicaciones al fomento de la vida y de los intereses materiales». De ahí «síguese la obligación inexcusable del Estado de estimular y promover la cultura, desarrollando una política científica». Ramón y Cajal, Santiago. Deberes del Estado en relación con la producción científica (Discurso de ingreso en la Real Academia de Ciencias). In: Los tónicos de la voluntad. Madrid: Espasa-Calpe; 1963, p. 133-156. 
Resultado de esta convergencia fue la adopción en enero de 1907 por el gobierno liberal de Segismundo Moret de una ambiciosa política de la ciencia cuyo principal hito fue la creación de una institución nacional con el objetivo de la modernización científica de España. Esta institución fue la Junta para la Ampliación de Estudios e Investigaciones Científicas (en adelante, JAE), que tuvo un papel central en el desarrollo científico español desde 1907 hasta el final de la Guerra Civil en 1939; aunque existieron otras iniciativas notables como el Institut d'Estudis Catalans en Barcelona.

La JAE fue fruto de la asunción por parte de Segismundo Moret del programa propuesto por los krausistas, expresado en la famosa carta que le dirigió Giner de los Ríos ${ }^{12}$. De hecho, a principios del siglo XX, krausistas, regeneracionistas, liberales, socialistas, e incluso algunos conservadores, estaban de acuerdo respecto a la necesidad de tomar medidas políticas que promovieran un desarrollo científico español homologable al alcanzado por otros países europeos y norteamericanos. Este acuerdo implicó prácticamente un pacto entre las élites que supuso un «discurso civil», en el sentido de Glick ${ }^{13}$. Se dio «una amplia base de apoyo a la ciencia pura» entre las

12. Giner escribió a Moret una carta (datada el 6 de junio de 1906) en la que subrayaba los puntos básicos de la política que creía que debía llevar a cabo el gobierno: formar nuevo personal de alto nivel lo más rápida e intensamente posible y fomentar la investigación con la creación de laboratorios y centros de alta calidad. La carta está reproducida en Castillejo, David, ed. Los intelectuales reformadores de España. Epistolario de José Castillejo, I. Un puente hacia Europa, 1896-1909. Madrid: Castalia; 1997, p. 326-330.

13. Para la definición de «discurso civil» véase, por ejemplo, Glick, Thomas, F. Einstein y los españoles. Ciencia y sociedad en la España de entreguerras. Madrid: CSIC; 2005, p. 9, 297. Sin embargo este «discurso civil» no incluyó a todas las élites; se puede admitir que «se configuró entre las élites un clima de opinión que valoraba positivamente a la ciencia» siempre que excluyamos a las derechas más radicales; Glick, n. 13, p. 9. Por otro lado, el «discurso civil» no sostuvo al contrato social para la ciencia que encarnaba la JAE ya que dicho contrato, primero, siguió el proyecto krausista de Giner y Castillejo situándose fuera de las universidades, al contrario de lo que planteaban lo regeneracionistas con Ramon y Cajal a la cabeza y, segundo, no fue bien visto ni apoyado por los conservadores como luego mostramos. Es cierto que Castillejo aspiraba a algo semejante a un «discurso civil» a través de la JAE cuando afirma explícitamente: «Era, pues, necesario, en medio de la contienda de las ideas, establecer una tregua y señalar un campo donde los luchadores de todos los bandos pudieran alimentar sus fuerzas, ya que este noble pugilato interno no dispensa de presentar la cultura española como una unidad digna de ser recibida en el sistema de la cultura universal. Había que constituir un organismo que pudiera merecer la confianza de todos los partidos y mantenerse á igual distancia de sus diferencias, estableciendo la serena continuidad de la obra á través de los vaivenes de la política, y encomendarle la formación del personal científico y docente que cualquier reforma ha de necesitar». Memoria correspondiente a los años 1910 y 1911. Madrid: Junta de Ampliación de Estudios; 1912, p. 7-8. Pero también es cierto que la JAE nunca fue 
élites, y destacados científicos e intelectuales demandaron el desarrollo de políticas para mejorar la situación de la ciencia en España. Por tanto, se demandó el apoyo del Gobierno a la ciencia (y la tecnología) promoviendo políticas adecuadas y asumiendo la necesaria financiación.

El acuerdo, sin embargo, no se hizo extensivo a los diversos aspectos en que debía concretarse la intervención del Estado. Ramón y Cajal y los regeneracionistas consideraban que la política científica a desarrollar debía centrarse en la renovación de las instituciones existentes, es decir, de las universidades públicas (los conservadores estaban de acuerdo en esto) ${ }^{14}$. En cambio para los krausistas, con Giner de los Ríos a la cabeza, era necesaria la creación de instituciones científicas y formativas externas a las universidades y autónomas respecto al Estado, cuyo papel debía limitarse a financiar el proyecto. Los krausistas siempre desconfiaron de las universidades y creyeron que la reforma debería basarse en nuevas instituciones científicas y educativas, externas al sistema universitario existente. El gobierno de Moret optó por esta segunda opción, determinando que la modernización científica (y, posteriormente, tecnológica) de España fuera independiente de las universidades. Con ese fin se creó la JAE por Real Decreto de 11 de enero de 1907 (en las últimas semanas de su gobierno). El Real Decreto indicaba las funciones y actividades de la JAE, la forma en que debía ser gobernada y su estatus como institución pública financiada por el Estado (dependiente del Ministerio de Instrucción Pública y Bellas Artes). El artículo primero del Real Decreto destacaba como principales funciones de la JAE: «El servicio de ampliación de estudios dentro y fuera

un organismo que lograra esa confianza de todos los partidos. Desde luego no la tuvo de los conservadores, ni de las derechas más radicales (aunque algunos se beneficiaran de sus becas y participaran en la JAE). Por otro lado, si entendemos por «discurso civil» «un discurso civil abierto sobre las ideas científicas», como señala Glick, n. 13. p. 297, (se dio respecto a las ideas científicas de Einstein en su viaje a España) el contrato social para la ciencia de 1907-1939 lo implicó ya que las ideas científicas eran comúnmente aceptadas. Si el discurso civil implicaba además las relaciones entre ciencia y política y un proyecto concreto como el de la JAE, no fue exactamente así. Véase también Glick, Thomas; Sánchez Ron, José Manuel. Science frustrated: The «Einstein Institute». Minerva. 2006; 44: 355-378.

14. Cajal afirma en 1987 en las acciones que propone como parte de la política científica del gobierno: «Transformar la Universidad, hasta hoy casi exclusivamente consagrada a la colación de títulos y a la enseñanza profesional, en un Centro de impulsión intelectual, al modo de Alemania, donde la Universidad representa el órgano principal de la producción filosófica, científica e industrial». Ramón y Cajal, Santiago. Deberes del Estado en relación con la producción científica (1987, discurso de ingreso en la Real Academia de Ciencias). In: Los tónicos de la voluntad. Madrid: Espasa-Calpe; 1963, p. 133-156. 
de España»y «El fomento de los trabajos de investigación científica» ${ }^{15}$. Dos semanas más tarde, se estableció y aprobó por el plenario de la JAE un reglamento interno.

La envergadura e importancia del proyecto que encarnaba la JAE implicó a destacados científicos como Santiago Ramón y Cajal, José de Echegaray, Luis Simarro, Ignacio Bolívar, José Rodríguez-Carracido o Leonardo Torres Quevedo, entre otros. También a intelectuales como Marcelino Menéndez Pelayo, Ramón Menéndez Pidal y José Castillejo. Dada su significación científica, el Premio Nobel Santiago Ramón y Cajal fue propuesto, desde el principio, como presidente, cargo que mantuvo hasta su muerte en 1934, fecha en que le sucedió Ignacio Bolívar hasta la disolución de la JAE en 1939. José Castillejo (discípulo predilecto de Francisco Giner de los Ríos) fue el secretario y auténtico gestor, organizador y ejecutor del proyecto que supuso la JAE. A través de José Castillejo, los krausistas Francisco Giner de los Ríos y Manuel Cossío ejercieron una considerable influencia sobre la JAE, aunque técnicamente nunca fueron miembros de ella.

El Decreto de 1907 estableció firmemente la independencia de la JAE, en lo que refiere a su organización y actuaciones. En dicho Decreto se consignó que «La Junta tendrá capacidad para adquirir, poseer y administrar bienes de todas las clases con destino a los fines para los que es creada». La JAE «determinará la distribución de las pensiones, el procedimiento para su concesión y los requisitos necesarios para optar a ellas [...]» y además fijará «la cuantía, la duración y el lugar de disfrute de la pensión [...]». Propondrá también los Delegados oficiales a los Congresos científicos y las subvenciones de que deberán disfrutar, y, finalmente, dispondrá de una Caja de investigaciones científicas ${ }^{16}$. En el Reglamento de funcionamiento interno aprobado en junio de 1907 se precisaba la organización y funciones de la JAE: la Junta mantendría la comunicación con centros extranjeros y españoles, fomentaría la investigación aprovechando los conocimientos adquiridos por los pensionados, debía también «reunir las fuerzas dispersas» y «aprovechar» a profesores extranjeros y además la Comisión

15. Real Decreto de creación de la Junta para la Ampliación de Estudios. Gaceta de Madrid, 15 Enero 1907: 166. En 1907 el presupuesto de la JAE fue de 328.000 pesetas, una suma enorme considerando el reducido presupuesto de las universidades. La cantidad del presupuesto de la JAE procede de: Memoria correspondiente al año 1907, Madrid: Junta de Ampliación de Estudios; 1908, p. 23.

16. Real Decreto de creación, n. 15, p. 166. 
ejecutiva «formará el oportuno proyecto» de creación de laboratorios y seminarios para la investigación que se someterá a la Junta Plena. La «Caja de investigaciones» financiaría la investigación, incluyendo «la instalación de Laboratorios, Seminarios y Centros Análogos» ${ }^{17}$.

La JAE satisfacía, pues, los objetivos expuestos por el ministro Amalio Gimeno cuando señalaba en el preámbulo del Real Decreto de 1907:

«[...] pero a fin de que todo esto sea eficaz, necesita tener esta obra un carácter nacional, llevándose a cabo de un modo perseverante y regular por un organismo neutral que, colocado fuera de la agitación de las pasiones políticas, conserve a través de todas las mudanzas su independencia y prestigio» ${ }^{18}$.

En el párrafo final de su exposición, afirmaba que la clave de la transformación radicaba en asegurar que a través de todos los cambios ministeriales «algunos hombres ilustres» estarían al frente del esfuerzo, ya que «como otras naciones, se ha comprendido que hay que liberar a ese organismo director de trabas administrativas, que produciendo una igualdad externa aparente, excluyen y sustituyen la acción personal directa con una acción oficial, que no suele ser rápida ni acertada» ${ }^{19}$.

Fueron, por tanto, los «hombres ilustres» y sus «acciones personales» los responsables de sacar adelante este proyecto, gestionando de forma independiente la financiación recibida, las becas, los centros y laboratorios que se fueron creando. Como se señalaba en la primera memoria de la JAE

«La Junta debía ser el organismo iniciador de una renovación intensiva y rápida de nuestra educación superior y nuestras investigaciones científicas, sobre la base de la comunicación con el extranjero, el trabajo desinteresado y la libertad de elección en materias y procedimientos» ${ }^{20}$.

La premisa básica fue que la formación científica y la producción de ciencia de prestigio exigían recursos e independencia científica, desde luego, pero también autonomía en la gestión y gobierno de la ciencia, y, por tanto, una clara línea divisoria entre ciencia y política. A cambio se esperaba ir alcanzando el nivel científico (y también tecnológico) de los

17. Reglamento de 16 de junio de 1907. Gaceta de Madrid, 22 Junio 1907: 1140.

18. Real Decreto de creación, n. 15, p. 166.

19. Real Decreto de creación, n. 15, p. 166.

20. Memoria, nota 15, p. 18. Todas las Memorias pueden consultarse en http://edaddeplata.org/ tierrafirme_jae/memoriasJAE/index.html 
países más avanzados, en otras palabras, se esperaba productividad y se daba por supuesta la integridad de los participantes en el proyecto. Así, pues, en el proyecto que perseguían los liberales es posible identificar los componentes de un contrato social para la ciencia española.

La concesión de becas de estudio constituyó un ámbito clave de actuación independiente al que se destinó buena parte de los fondos gestionados por la $\mathrm{JAE}^{21}$. Las becas eran adjudicadas de acuerdo con criterios establecidos por la JAE. Por otro lado, la JAE era libre para decidir quién debía permanecer investigando y qué retribuciones recibían. Podía, además, contratar de entre los estudiantes becados en el exterior a los que se considerara que debían quedarse investigando en la institución ${ }^{22}$. Esta posibilidad fue incluida en el Reglamento de funcionamiento interno de 1907, cuyo artículo 40 establecía:

«la Junta podrá exigir de los pensionados no pertenecientes al profesorado que al terminar la pensión o regresar del extranjero se dediquen durante cierto tiempo, mediante la remuneración que aquella proponga, a trabajos de investigación y enseñanza en armonía con las aficiones de cada uno, bajo la dirección de un delegado de la Junta» ${ }^{23}$.

La actividad científica, los centros de investigación y los científicos designados para situarse al frente de ellos fueron responsabilidad de la Junta. Este amplio grado de autonomía concedido a la JAE por los liberales fue un punto de controversia con los conservadores a lo largo de la historia de la institución. En términos generales, cabe afirmar que en las etapas conservadoras se tendió a limitar esta autonomía, mientras que liberales y republicanos la respetaron, aunque se produjo también algún roce puntual ${ }^{24}$. La mencionada controversia suscitó un importante debate

21. Real Decreto de creación, n. 15, p. 166.

22. La JAE también actuó con independencia en relación a los centros de investigación y los científicos designados para desarrollarlos. Para este tema véase González, Francisco; Fernández, Rosario. Nuevas perspectivas en torno a la política de pensiones de la Junta para la Ampliación de Estudios: modelos de encuentro con Europa de la universidad española. Revista Complutense de Educación. 2002; 13 (2): 563-593. Es interesante su noción de "generación tutelada» referida a los jóvenes científicos que fueron fuertemente apoyados y promocionados en el contexto de la JAE.

23. Reglamento, n. 17, p. 1140.

24. Laporta, Francisco; Solana, Javier; Ruíz Miguel, Alfonso; Zapatero, Virgilio; Rodríguez de Lecea, Teresa. Los orígenes culturales de la Junta para Ampliación de Estudios. Arbor. 1987; 126 (núm. 493): p. 38, señalan que en 1913 se dio una batalla entre la Junta y el Ministro de Instrucción Pública Ruíz Jiménez ya que éste pretendía que la Junta subvencionase a dos 
que tuvo como trasfondo concepciones muy diferentes de la política de la ciencia que necesitaba el país, de las relaciones entre ciencia y política y del gobierno de la ciencia.

\section{El control político de la JAE: la frontera entre ciencia y política}

El 25 de enero de 1907, dos semanas después de la creación de la JAE, los conservadores llegaron al poder. Faustino Rodríguez San Pedro fue el Ministro de Instrucción Pública y Bellas Artes en el nuevo gobierno presidido por Antonio Maura. Durante los tres años de gobierno de Maura, Rodríguez San Pedro planteó importantes problemas al proyecto que encarnaba la JAE.

El primer movimiento del nuevo ministro fue modificar el reglamento interno de la JAE en todo lo relacionado con su autonomía. Estas modificaciones «supusieron un cambio radical en el carácter y funciones de este organismo» ${ }^{25}$. Las principales modificaciones fueron: a) todos los acuerdos de la Junta «Se someten al ministro para su aprobación no solo los presupuestos, sino los asuntos de orden puramente científico [...]» ${ }^{26}$, y «hasta las decisiones técnicas, [...] y la aplicación de recursos no procedentes del Estado» ${ }^{27}$; b) todas la becas para estudios en el extranjero tenían que ser sometidas al ministro para su aprobación; c) una lista de tres nombres debía ser presentada al ministro, tanto para las becas como para los nuevos miembros; el ministro se reservaba el derecho a tomar la decisión final (en ciertos casos podía decidir sin la terna previa de la JAE); y d) el presupuesto de la JAE fue reducido de 328.000 a 150.000 ptas. Finalmente, en relación a las becas de estudio en el extranjero (que ese año casi no se concedieron), el ministro recordaba que, a pesar de que estaban incluidos en la ley de presupuesto, los fondos para estas becas dependían de la decisión política.

Esta intervención se mantuvo a lo largo del gobierno conservador. Incluso se establecieron controles más estrictos para la concesión de becas con los decretos de 9 de junio de 1908, 10 de julio de 1909 y 29 de enero de 1909.

delegados a congresos científicos nombrados por él. Pero este es un tipo de roce muy distinto a los que supusieron los gobiernos conservadores que desconfiaban de la JAE y todo lo que significaba.

25. Memoria, nota 15, p. 6.

26. Castillejo, n. 12, p. 350 .

27. Castillejo, n. 12. p. 351. 
La JAE ahora sólo podía proporcionar una lista de materias preferentes (dando prioridad a aquellas no enseñadas en España). Las solicitudes se dirigirían a través de los «establecimientos docentes a que perteneciesen los candidatos» o en los que siguiesen sus estudios, y tenían que estar acompañadas de un «informe de los Claustros respectivos» ${ }^{28}$. De esta manera, la propuesta de la JAE era contrapesada por el informe de las universidades.

El gobierno conservador atacaba, por tanto, en dos frentes: la restricción de la autonomía de la JAE y el sometimiento de las solicitudes de becas a las universidades, sobre las que tenía un considerable control a través del cuerpo de catedráticos. De esta manera, la frontera entre ciencia y política, que había sido establecida por el gobierno liberal, quedaba debilitada. La política conservadora disolvía en parte esta frontera y limitaba la autonomía de la JAE. De hecho, el nuevo ministro intentó reducir a la JAE a un mero cuerpo consultivo más que ejecutivo.

La reacción liberal a las medidas del gobierno conservador no se hizo esperar y dio lugar a un importante debate parlamentario. Este debate se sostuvo a lo largo de la existencia de la JAE en la medida en que los enfrentamientos entre las dos posiciones se mantuvieron en los diferentes gobiernos (de un signo u otro) hasta prácticamente la Guerra Civil. En esta primera etapa el debate comenzó cuando el anterior ministro Amalio Gimeno, ahora en la oposición, cuestionó las medidas tomadas por el nuevo ministro Rodríguez San Pedro ${ }^{29}$. Otros destacados parlamentarios liberales también tomaron parte en el enfrentamiento. El principal argumento liberal consistió en subrayar la importancia de la JAE y señalar la necesidad de mantener su autonomía y auto-gobierno sobre la base de la autoridad científica. Gimeno planteaba explícitamente la cuestión: «Su Señoría no ha comprendido todavía el pensamiento de creación de la Junta, ni para qué se inició ésta, ni para lo que es, ni lo que significa, ni lo que va a hacer» ${ }^{30}$.

Respecto a la obligación de presentar tres candidatos para que el ministro tomara la decisión final, Gimeno consideraba que esta medida daría cabida a la arbitrariedad y capricho ministerial, ya que permitía «poder nombrar a un amigo que ocupe el tercer lugar en el segundo o en el primero» ${ }^{31}$. Lo que

\footnotetext{
28. Real Decreto de 29 de enero de 1909. Gaceta de Madrid, 30 Enero 1909: 263-264.

29. Ver este debate en Laporta; Solana; Ruíz Miguel; Zapatero; Rodríguez de Lecea, n. 24, p. 1831. Su análisis del debate ha sido tomado en cuenta en las siguientes páginas.

30. Diario de Sesiones de Senado 1907; no 93, sesión 14 Noviembre 1907: 1851.

31. Diario de Sesiones, n. 30.
} 
argumentaba Gimeno era que si tales decisiones se dejaban a los políticos se perdería la objetividad y la integridad que caracterizaban a las decisiones científicas, puesto que éstas quedarían sometidas a redes de influencia. Esto no ocurriría con los científicos, cuya integridad y objetividad eran consideradas incuestionables y muy superiores a las ministeriales. Ellos eran los que debían decidir a quiénes se concedían las becas de estudio, cómo se distribuían los recursos o qué centros de investigación debían desarrollarse.

Los liberales estaban convencidos de que la ciencia debía ser gobernada por los científicos puesto que esto garantizaba la buena ciencia y la buena gestión de la misma ${ }^{32}$. Los conservadores creían que también debían hacerlo los representantes políticos, pues la ciencia debía quedar bajo control público $^{33}$. Los conservadores, además, entendían que la JAE era un proyecto político liberal (idea original de los krausistas de la Institución Libre de Enseñanza ${ }^{34}$ ) en cuyo seno se decidía y actuaba política e ideológicamente, por más que importantes científicos formaran parte de él.

Estas dos formas opuestas de entender a la JAE se enfrentaron en repetidas ocasiones a lo largo de todo el periodo de su existencia ${ }^{35}$. Los gobiernos conservadores se caracterizaron por sucesivos intentos, más o menos exitosos, de controlar la institución, mientras que los gobiernos liberales fueron favorables en general a preservar la autonomía que caracterizaba al proyecto inicial. El debate entre liberales y conservadores sirvió para definir claramente las posiciones sostenidas por ambos acerca de las relaciones entre Estado y ciencia. Para los liberales ciencia y política eran dos esferas separadas que colaboraban en el objetivo de conseguir

32. Prueba de ello es que el primer año de la JAE fue poco productivo en calidad científica.

33. En Estados Unidos se da una fuerte injerencia política en la ciencia a partir de los años setenta. Según Guston la política de la ciencia en los Estados Unidos ha pasado del modelo del contrato social a un nuevo régimen político. Este nuevo régimen se caracteriza por la injerencia cada vez más fuerte de la política en la ciencia. Guston, n. 1., p. 144.

34. La Institución Libre de Enseñanza fue fundada por Giner de los Ríos in 1876. Importantes liberales y republicanos fueron educados en la ILE. La influencia de la ILE y de los krausistas se hace palpable a comienzos del siglo XX cuando algunos de sus más prominentes figures jugaron un papel clave en la JAE. Véase Cacho Viu, Vicente. La Institución libre de enseñanza. I Orígenes y etapa universitaria (1860-1881). Madrid: Ediciones Rialp; 1962. Jiménez Landi. La Institución Libre de Enseñanza y su ambiente. Madrid: Universidad Complutense; 1996.

35. En 1910, cuando cae el Gobierno de Maura, la JAE recupera autonomía, se consolida y expande. Véase Laporta; Solana; Ruíz Miguel; Zapatero; Rodríguez de Lecea, n. 24, p. 32-42. Un periodo marcado por la alternancia de gobiernos liberales y conservadores hasta la dictadura de Primero de Rivera (1923-1931) y finalmente la democracia de la Segunda República hasta el final de la Guerra Civil. 
un bien público necesario para el desarrollo y el progreso del país, y esta colaboración se basaba en la autonomía e implicaba confianza mutua. Los criterios y valores internos de la ciencia se consideraban mucho más adecuados que los políticos para gestionar los diversos aspectos implicados en el desarrollo de la ciencia, incluyendo su gobernanza. Para los conservadores, esta confianza era infundada ya que la gobernanza de la ciencia implicaba siempre criterios políticos y, de hecho, esto era lo que ocurría en la JAE. En consecuencia, a) la administración de los recursos disponibles y la gestión de la ciencia no podían dejarse enteramente en las manos de los científicos, los políticos debían intervenir y controlar; y b) la idea de una institución completamente independiente de los intereses partidistas, e incluso de los intereses de grupo, era inconcebible; no importaba con qué fuerza se afirmara lo contrario en la JAE. El debate dejó bien claro que para los conservadores la idea de separar ciencia y política era en sí misma una idea política. La JAE operaba a través de redes de relaciones políticas y personales, exclusivas y parciales y era, por tanto, partidista.

\section{Las redes de influencia y el partidismo de la JAE: problemas de integridad}

En consonancia con las posiciones liberales, la JAE aspiraba a no ser partidista y se presentaba como un proyecto que trascendía los posicionamientos políticos ${ }^{36}$. Al mismo tiempo era firme defensora de la moral de la ciencia que suponía una esfera pública basada en la independencia de criterio, la integridad, la objetividad, la atención al mérito y a la razón frente a las redes de influencia, el privilegio, la corrupción, la demagogia, etc. ${ }^{37}$. A pesar de ello, el partidismo fue una realidad en algunos ámbitos de la actuación de la JAE. En primer lugar porque no se pudo evitar su alineamiento político con los liberales - después de todo era un proyecto liberal-y, en segundo, porque de hecho existieron redes de relaciones que influyeron, al menos en la concesión de becas para estudios en el extranjero. Esta situación fue alimentada por la autonomía otorgada a la JAE que le permitía operar al margen de las jerarquías y procedimientos consolidados en las universidades,

36. Tal como señala con claridad Castillejo en Memoria, n. 13, p. 7-8.

37. Esta moral fue defendida por los krausistas, los positivistas y los regeneracionistas, entre otros. 
lo que dejaba un amplio margen para la discrecionalidad y la aplicación de criterios propios.

Esta discrecionalidad estaba integrada en los criterios que operaban en la concesión de becas de estudio para el extranjero (y España). Tales criterios incluían aspectos objetivos como la presentación de los méritos que se aducían al solicitar la beca, pero también, y de forma destacada, aspectos subjetivos consistentes en consideraciones cualitativas y discrecionales. José Castillejo, el secretario de la JAE, defendía al respecto que los criterios para la concesión de becas de estudio se modificaban de acuerdo con las tendencias internacionales,

«(...) sustituyendo el examen momentáneo y puramente intelectual, o el concurso de méritos oficiales, por un juicio en el cual esos elementos podían ser, cuando más, un indicio, porque debía basarse en el conjunto de circunstancias individuales de orden científico y moral, de aptitud y vocación, así como en consideraciones objetivas de orden social y pedagógico» ${ }^{38}$.

En la correspondencia que mantuvo Castillejo con diversos personajes del momento y en relación a importantes aspectos de la JAE puede detectarse la actuación de esta red de relaciones ${ }^{39}$. Así, por ejemplo, Castillejo escribía a Manuel Cossío en 1907 respecto a la lista ya elaborada de 72 solicitantes de becas:

«Quisiera que si Vd. tiene tiempo echase una ojeada. Porque Vd. conocerá muchos, especialmente maestros, y puede darme confidencialmente informes lo mismo de los que considera Vd. incapacitados que de los que considera Vd. capaces para el caso. Me convenzo plenamente de que solicitudes, trabajos presentados, etc. nada valen comparados con diez minutos de conversación -Uno de los que más folletos, libros y trabajos presentan vino ayer a verme y me dejó desencantado. Todo el tipo de un vividor sin ideal ni formación. Como Vd. conocerá muchos de visu o por buenas referencias, creo su testimonio indispensable. Ya comprenderá que tendré cuidado del uso que hago de él» ${ }^{40}$.

Aún en los periodos de intervención gubernamental, esta red permaneció activa en el caso de las becas para estudios en el extranjero. Un

\footnotetext{
38. Memoria, n. 15, p.16.

39. Esta correspondencia muestra fehacientemente lo que indicamos antes, la influencia de Giner y Cossío en la JAE a través de su secretario, Castillejo.

40. Castillejo, n. 12, p. 382.
} 
ejemplo de ello lo encontramos en la amistosa carta que el institucionista Josep Pijoan, secretario del Institut d' Estudis Catalans, remitió a Castillejo (21 de junio de 1907) solicitando una beca, mientras hablaba acerca de dónde pasar el verano:

«[...] ¿Qué harán VV? Si Don Francisco [Giner de los Ríos] fuera a un sitio aceptable puede ser que me dejaría caer. Si su Junta me facilitase una pensión para ir cuatro meses a París también ${ }^{41}$.

Otro ejemplo en este sentido fue la carta que Elvira Alonso remitió a Castillejo desde París, en respuesta a una amistosa misiva de éste:

«Como ya dije a V. tengo gran interés en ir a Inglaterra, y en este caso, desearía que la persona que Vds. enviasen a Tolosa (Toulouse) fuera de absoluta confianza $[\ldots] »^{42}$.

El 18 de agosto de 1907 Castillejo escribió a Giner de los Ríos sobre ciertas cuestiones organizativas señalando algunos nombres que, desde el principio, contaban para las actividades de la JAE:

"Querido Don Francisco: ¿A quién acudiremos de confianza para cosas de música $\left.{ }_{i}\right)_{i}$ Quizás a Roda? Sería este un incondicional como candidato en terna para vocal de la Junta? No lo he tratado bastante $-i$ A quién para cosas de arquitectura en Madrid? ¿Y para artes y oficios y artes industriales?» ${ }^{43}$.

Y más adelante, añade: «Para llevar muchachos, si les conviene, pagándoles pensión de viaje etc. pensaba en del Río, Barnés, Palacios, Zulueta, Acebal, etc. Cajal dijo que sí a todo» ${ }^{44}$.

Castillejo hacía explícita la cuestión de las recomendaciones en esa misma carta al decir a Giner: «Recibo cartas de recomendación (no muchas).

\footnotetext{
41. Castillejo, n. 12, p. 349.

42. Castillejo, n. 12, p. 365.

43. Castillejo, n. 12, p. 368.

44. Castillejo, n. 12, p. 349. Como señala Sánchez Ron, Castillejo sabía cómo tratar con Cajal y con sus superiores en el Ministerio. Sánchez Ron, José M. Encuentros y desencuentros: relaciones personales en la JAE. In: Sánchez Ron, J.M.; García-Velasco, J., eds. 100 años de la JAE. La Junta para la Ampliación de Estudios e Investigaciones Científicas en su Centenario. Madrid: Publicaciones de la Residencia de Estudiantes —Fundación Francisco Giner de los Ríos— ILE; 2010, p. 95-215 (p. 106).
} 
He optado por contestarlas» ${ }^{45}$. Giner le advertía que pisase el terreno de las recomendaciones con cuidado para no ofender a nadie y le recordaba que Luis Montoto (notario eclesiástico y concejal del ayuntamiento de Sevilla) fue recomendado y así obtuvo su pensión ${ }^{46}$. En una carta de 22 de agosto de 1907, Giner le decía a Castillejo:

«Otro sí sobre las recomendaciones. Como en nuestro tiempo y pueblo todo es asunto de favor, lo mismo Cossío que yo creemos que no debe V. extremar las cesuras contra los que apelan...» ${ }^{47}$.

En el caso de Luís Montoto, fue su padre quien optó por recurrir a Santiago Magdalena, Dean de la Santa Iglesia Prioral en Ciudad Real, para que en virtud de su relación con Castillejo recomendara a su hijo para la obtención de una pensión (8 de agosto 1907):

« Se nos cayó la sopa en la miel! El Sr. Castillejo es el secretario y el alma de la Junta de ampliación de estudios que propone para las pensiones en el extranjero. Mucho espero, por tanto, de la recomendación de usted» ${ }^{48}$.

Santiago Magdalena escribió con toda claridad a Castillejo acerca de esta recomendación:

«Mi distinguido amigo, hace días un compadre mío de Sevilla me pedía una recomendación para su hijo que pretende pensión para estudiar o ampliar estudios en el Extranjero y me acordé que V. podía favorecernos y así lo indicaba a mi dicho compadre el Notario Mor. Del Arzobispado de Sevilla, que me contesta $[\ldots] »^{49}$.

Tras destacar la valía del muchacho, escribía: «Mucho le agradeceré que sea preferido a otros participantes mi recomendado Luis Montoto y Sedas por lo que le anticipo expresivas gracias, saludando a su familia su afectísimo amigo $[\ldots] \gg{ }^{50}$. 
Una de las redes de influencia, que a menudo fue señalada por los conservadores en sus críticas, actuaba en el ámbito de lo que se ha denominado como "la institución difusa», es decir, las conexiones entre la ILE y la JAE ${ }^{51}$. Esta red era activa en la concesión de becas de estudio, tanto que el número de becados del entorno de la ILE llegó a ser alarmante. Este hecho supuso una llamada de atención de Francisco Acebal, el ayudante de Castillejo en la secretaría de la JAE. Según cuenta David Castillejo,

«Acebal se fue de vacaciones, y desde Asturias dio un primer aviso de alarma: faltaría gente a la Institución si salían tantos al extranjero. El aviso escondía otro temor: que demasiada gente de la Institución se estaba aprovechando de las pensiones [...] Giner reaccionó enérgicamente; fue, quizá, la única ocasión en que se sintió moralmente criticado por falta de imparcialidad» ${ }^{52}$.

Acebal escribió a Castillejo, «Me preocupa un poco, y aún un mucho, la cantidad de profesores de la Institución que van a salir de España; y preveo que tendremos que acudir a reforzar el cuadro» ${ }^{53}$.

Un ejemplo muy posterior que, junto a otros, demuestra la continuidad de la red de influencias fue la beca concedida a Rafael Alberti. En 1931 Alberti, quien mantenía amistad con Menéndez Pidal, ya que ambas familias sostenían relaciones desde hacía años, le escribía desde París solicitando su ayuda para una beca ${ }^{54}$. Pidal trasladó al presidente de la JAE la petición y la Junta acordó conceder a Alberti una beca de cuatro meses en Francia. Como señala Sánchez Ron, «en el correspondiente expediente de la JAE sólo aparece como petición del interesado una breve nota sin fechar» ${ }^{55}$. Posteriormente, Alberti obtuvo una prórroga de seis meses para viajar por Alemania, Polonia y Rusia.

El tratamiento preferencial recibido por aquellos que formaban parte de las redes de relaciones plantea la cuestión de en qué medida este tipo de actuación fue en detrimento de las solicitudes de personas externas a dichas redes. La correspondencia entre los implicados revela que el temor

\footnotetext{
51. Término introducido por Zulueta para referir a la influencia de la ILE en otras instituciones a través de las personas formadas en ella. Zulueta, Luís. Lo que nos deja D. Francisco. Boletín de la Institución Libre de Enseñanza. 1915; 39: 48-56.

52. Castillejo, n. 12, p. 377.

53. Castillejo, n. 12, p. 378.

54. Carta de 5 de agosto de 1931, en Sánchez Ron, n. 44, p. 140.

55. Sánchez Ron, n. 44, p. 141.
} 
de Gimeno de que el ministerio pudiese privilegiar a conocidos a la hora de la concesión de las becas alcanzaba a la misma JAE. Desde el punto de vista de la teoría del contrato social para la ciencia, lo que estaba en juego en esta situación era un problema de «integridad» en la gestión de los recursos que contradecía los principios y valores que «teóricamente» encarnaba la JAE y que sus miembros asumían como propios. Este problema de integridad se extendía a la gestión de los fondos públicos asociados a estas becas, es decir, tenía consecuencias económicas.

Por supuesto que la actuación de este tipo de redes debe ser situada en su contexto histórico y no debe olvidarse que ésta no era una forma poco habitual de funcionamiento en ese momento. Pero, primero, ello no elimina el problema de integridad señalado y, segundo, los miembros de la JAE, en teoría al menos, rechazaban esta práctica y los valores a ella asociados, defendiendo públicamente los valores propios de la «moral de la ciencia» que desde finales del XIX fueron la bandera de la regeneración y modernización de España, de la cual la JAE era su máxima expresión.

Se podría también circunscribir el problema de integridad a la actuación de algunos pocos miembros de la JAE. Pero, aunque las redes operasen a través de ciertas personas concretas, resulta muy difícil exonerar a la JAE, pues las propuestas de becas de estudio eran elaboradas por la Comisión Ejecutiva - de la que eran miembros el presidente de la JAE, es decir, Ramón y Cajal, el secretario, Castillejo, además de dos vicepresidentes y dos vocales - y eran aprobadas por la Junta Plena de la JAE, formada por los 21 vocales y el secretario ${ }^{56}$. Esto demuestra, como es bien sabido, que ni las instituciones, ni las comunidades científicas actúan exclusivamente según los valores asumidos en la concepción idealizada de la ciencia y de

56. Real Decreto de 22 de junio de 1907. Gaceta de Madrid; 22 Junio 1907: 1140, Según el artículo 26: «La Comisión ejecutiva examinará las solicitudes y formulará las propuestas [...]. Estas propuestas determinarán para cada pensionado, la cuantía y el tiempo de la pensión [...]»; artículo 27: «Las propuestas, de tal manera formuladas, se someterá a la Junta y con su acuerdo se elevarán al Ministerio para su resolución definitiva, en lista que comprenda, siempre que sea posible, triple número de nombres que de pensiones». Esto último es lo que tanto discutió la JAE de este Decreto por el que se aprobaba el Reglamento interno de la JAE. En 1910 ya en el gobierno liberal se modifican los anteriores decretos en el Real Decreto de 22 de enero de 1910, y se afirmó respecto al tema aquí tratado: Art. 26 «La comisión ejecutiva examinará las solicitudes y llevará a la Junta [...] el proyecto de propuestas, determinando para cada pensionado la cuantía y duración de la pensión y lo que debe abonársele para gastos de viaje. Art. 27, Aprobado el proyecto por la Junta, se elevarán al ministro, para su resolución definitiva, las correspondientes propuestas». Gaceta de Madrid; 28 enero 1910: 199. 
su práctica que teóricamente ellas mismas sostienen y apoyan. Este fue el caso en el contrato social para la ciencia española y la JAE.

\section{La gestión de los fondos}

Los conservadores fueron críticos durante años con la gestión de los recursos económicos de la JAE que consideraban demasiado libre y que, a su juicio, presentaba problemas de rendición de cuentas. En 1912 el ministro liberal Amalio Gimeno (entonces en el gobierno) fue acusado por los conservadores de despilfarrar dinero del presupuesto general. El ministro fue criticado por la falta de control presupuestario de la JAE y, también, por su empleo de créditos para fines generales no especificados. Gimeno se limitó a responder que la JAE tenía una asignación de la que podía disponer libremente y que por ello no incumplía la ley ${ }^{57}$. Pero, de hecho, lo que era realmente criticado es que esa partida quedaba al margen del control parlamentario y que se donaba libremente para que la Junta «lo emplee a su capricho» ${ }^{58}$.

Este tema volvió a surgir en 1918 en un ruego que formuló el diputado conservador Pío Zabala incidiendo en la habilidad de la JAE para lograr la inclusión en la ley de Presupuestos «de un artículo en que sin especificar, sin determinar las partidas que la Junta administra, se sustrae al examen de las Cámaras la idea exacta del destino de aquellas sumas $[\ldots] »^{59}$. Zabala también solicitó respecto a la JAE que el «Sr. Ministro de Instrucción Pública se sirva traer las nóminas del personal que presta servicios en la Junta y en los Centros que de ella dependen, y además una relación especificada de los sueldos del Estado que dichos señores perciben [...]» ${ }^{60}$. José María González Echávarri (senador y catedrático) presentó una Memoria del Tribunal de Cuentas con la que se pretendía mostrar que la JAE no rendía cuentas suficientemente ${ }^{61}$. En el mismo sentido, el senador Archilla afirmaba que «La JAE goza en varios órdenes de privilegios no justificados, entre otros no tener que pasar sus cuentas el de que sus cuentas no pasan, como las de los demás Centros oficiales por el Tribunal de cuentas» ${ }^{62}$.

57. Laporta; Solana; Ruíz Miguel; Zapatero; Rodríguez de Lecea, n. 24, p. 37.

58. Diario de Sesiones del Congreso 1911-1912; n. 96, Sesión 29 Febrero 1912: p. 2616.

59. Diario de Sesiones del Congreso 1918, n.22, Sesión 19 Abril 1918, p. 503.

60. Diario de Sesiones, n. 59.

61. Laporta; Solana; Ruíz Miguel; Zapatero; Rodríguez de Lecea, n. 24, p. 58.

62. Diario de Sesiones del Congreso 1918; apéndice, n 74, Sesión 12 Julio 1918: 1226. 
La respuesta de los liberales consistió en negar las acusaciones y afirmar que todo había sido hecho de conformidad con la ley. José Casares (científico de la JAE y diputado) respondió a las críticas reconociendo que la JAE tenía dos tipos de asignaciones: una que era una subvención que no se tenía que justificar y se administraba libremente y otra que se tenía que justificar oficialmente. Había, por tanto, dotaciones libres de control, aunque Casares mantuviese que no creía que este tipo de subvención debiera administrase libremente, y recordaba que la Junta daba cuenta de todo detalladamente, aun cuando no estuviese obligada a ello ${ }^{63}$. El ministro liberal Santiago Alba (con el que Castillejo tenía una excelente relación) recordaba la independencia de la JAE del Ministerio de Instrucción Pública y la transparencia de sus cuentas $^{64}$. González Echávarri se mantuvo en su posición inicial y señaló que de las respuestas dadas se deducía que la JAE gozaba de privilegios en la administración de sus fondos y que su proposición de ley pretendía acabar con esos privilegios ${ }^{65}$. De hecho, la cuestión de cómo eran gestionados los recursos económicos y los exenciones de la JAE en este terreno permanecieron durante años en el corazón del debate parlamentario.

Las acusaciones formuladas por los conservadores eran graves y muestran la tensión política e ideológica generada en torno a la JAE. La interpretación dominante de los hechos en cuestión ha sido entender, básicamente, que las críticas conservadoras eran ataques sin fundamento. Sin embargo, lo cierto es que la JAE podía administrar de forma muy liberal ciertas partidas, por lo que gozaba de una situación privilegiada en la administración de sus fondos (aunque rindiese cuenta de ellos) y esto tenía un significado muy distinto para conservadores y liberales dadas sus muy diferentes formas de entender el proyecto que la JAE encarnaba.

\section{Conclusiones}

El debate en torno a la JAE entre conservadores y liberales ha sido analizado por los historiadores y otros especialistas quienes generalmente han tendido a considerar las acusaciones conservadoras como ataques políticos e ideológicos. Sin embargo, como hemos visto, esto no fue del todo así en

63. El discurso de Casares fue muy largo. Diario de Sesiones, n. 62, p. 1219.

64. Diario de Sesiones, n. 62, p. 1224.

65. Laporta; Solana; Ruíz Miguel; Zapatero; Rodríguez de Lecea, n. 24, p. 63. 
el caso de la red de influencias y la libertad con la que la JAE podía administrar ciertas partidas económicas.

Por otro lado, más allá de los problemas esbozados, la trayectoria de la JAE fue productiva y brillante. El contrato social para la ciencia que encarnó permitió un desarrollo científico antes nunca alcanzado y, por mucho tiempo, no igualado. Los científicos habían cumplido su parte del contrato en lo que respecta a la productividad como lo demuestra la larga lista de logros de la JAE.

Las redes de influencia operaron en la concesión de pensiones, pero no afectaron a la totalidad del amplio número de beneficiarios de estas becas que supusieron un importante impulso para la formación científica del país. Hay que tener en cuenta que en los 31 años de su existencia se concedieron 3.150 becas de las cuales 1.723 fueron para el extranjero, en diferentes universidades internacionales de prestigio, sobre todo europeas, y laboratorios. Estas becas, además de una formación científica de alta calidad ayudaron al desarrollo de redes de relaciones científicas internacionales de gran importancia para los científicos españoles ${ }^{66}$. Se crearon centros científicos y laboratorios bien dotados en los que se llevó a cabo una investigación de alta calidad ${ }^{67}$. Eran espacios puramente investigadores y en ellos trabajaban pensionados y científicos destacados. Científicos como Enrique Moles, Miguel Catalán, Blas Cabrera, Severo Ochoa o Antonio de Zulueta hicieron aportaciones científicas originales internacionalmente reconocidas. Por tanto, la JAE contribuyó a consolidar una élite científica española homologable internacionalmente que elevó la investigación científica española a cotas antes no alcanzadas (con la excepción del Premio Nobel Ramón y Cajal). La JAE también desarrolló una interesante política de publicaciones e impulsó la celebración de actividades internacionales por lo que científicos eminentes viajaron a España (incluyendo a Madame Curie y Albert Einstein).

Finalmente, el análisis de la política de la ciencia española del primer tercio del siglo XX tiene interesantes consecuencias sobre el modelo del contrato social para la ciencia. En primer lugar, confirma que es posible de-

66. Véase archivo Edad de Plata, accesible en http://archivojae.edaddeplata.org/jae_app/JaeMain. html.

67. Para un resumen del desarrollo de la red de centros de la JAE, véase Canales Serrano, Antonio Francisco; Corrales, Capi. El campus que nunca fue. In: Alcalá, Paloma; Corrales, Capi; López, Julia, coords. Ni tontas, ni locas. Las intelectuales en el Madrid del primer tercio del siglo XX. Madrid: FECYT; 2009, p. 106-127(p. 109). 
fender su existencia antes de la Segunda Guerra Mundial, por lo que puede ser usado válidamente para analizar las relaciones entre ciencia y política de comienzos del siglo XX. En segundo, los resultados apoyan la idea de que los problemas de frontera e integridad ya estuvieron presentes en esta primera versión del contrato, mucho antes, por tanto, de la década de los setenta en la que habitualmente se les sitúa. Debe resaltarse, sin embargo, que estos problemas no cuestionaron el éxito del contrato social para la ciencia en España, ya que la autonomía científica sólo fue puesta en cuestión en ciertas etapas a lo largo de la historia del contrato y los problemas de integridad estuvieron relacionados no con la investigación, sino con la formación científica y la distribución de cierto tipo de recursos para ella. Por tanto, las relaciones entre ciencia y política que determinaron el desarrollo científico del primer tercio del siglo XX en España constituyeron un contrato social para la ciencia que, a pesar de sus vicisitudes, fue productivo y exitoso.

El modelo del contrato social aplicado al caso español muestra algo bien conocido: que no hay que confundir la validez de los modelos con el hecho de que al ser abstracciones e idealizaciones no siempre, ni en todos sus aspectos, los hechos se comportan según los modelos ${ }^{68}$. Por tanto, y como señala Mäki, no es problemático que se juzgue como válido o incluso verdadero un modelo que «no refleje toda la verdad» acerca del sistema representado; por ejemplo, «los economistas emplean tales modelos a menudo entendiendo que dan acceso a información importante sobre la realidad económica» ${ }^{69}$. Esto es lo que ocurre con el modelo del contrato social para la ciencia que ha permitido reinterpretar hechos bien conocidos bajo una nueva luz haciendo visible ciertos aspectos de los mismos antes poco considerados; de ahí, su relevancia para el análisis histórico de las relaciones entre ciencia y política desarrolladas en diferentes países.

68. Mäki no considera esto un problema, más aún, el autor enfatiza que los modelos teóricos permiten obtener información sobre los sistemas representados en virtud del aislamiento logrado mediante idealización. Mäki, Uskali. Isolation, idealization and truth in economics. Poznan Studies in the Philosophy of Sciences and Humanities. 1994; 38: 147-168. Mäki, Uskali. Remarks on models and their truth. Storia del Pensiero Economico. 2006; 1: 7-19. Giere considera que los modelos carecen de valor veritativo por no ser entidades lingüísticas, pero son fundamentales en ciencia. Giere, Ronald. How models are used to represent reality. Philosophy of Science. 2004; 71: 742-752.

69. Mäki, Uskali. Models and the locus of their truth. Synthese. 2011; 180: 47-63 (48). 